Supporting information

\title{
Two- and Three-Dimensional Physical-Chemical Characterization of CER[AP]: A Study of Stereochemistry and Chain Symmetry
}

\author{
Fabio Strati ${ }^{1}$, Joana S. L. Oliveira ${ }^{2}$, Lukas Opalka ${ }^{3}$, Tetiana Muhkina ${ }^{4}$, Bodo Dobner ${ }^{5}$, Reinhard H. \\ H. Neubert ${ }^{1}$, Gerald Brezesinski ${ }^{1 *}$ \\ ${ }^{1}$ Institute of Applied Dermatopharmacy at Martin Luther University Halle-Wittenberg, Weinbergweg 23, D- \\ 06120 Halle (Saale), Germany \\ ${ }^{2}$ Max Planck Institute of Colloids and Interfaces, Colloid Chemistry Department, Wissenschaftspark \\ Potsdam-Golm, Am Mühlenberg 1, 14476 Potsdam, Germany \\ ${ }^{3}$ Charles University, Faculty of Pharmacy in Hradec Kralove, Akademika Heyrovskeho 1203, Hradec \\ Kralove, 500 05, Czech Republic \\ ${ }^{4}$ Institute for Condensed Matter Physics, Technical University Darmstadt, Hochschulstraße 8, 64289 \\ Darmstadt, Germany \\ ${ }^{5}$ Martin-Luther-University Halle-Wittenberg, Institute of Pharmacy, Wolfgang-Langenbeck-Strasse 4, 06120 \\ Halle (Saale), Germany
}

\section{Symmetric and Asymmetric CER[AP]}

\subsection{Synthesis and separation of asymmetric CER[AP]}

The synthesis of CER[AP] with a C24 chain is conducted as described in the following passage. $2.5 \mathrm{~g}(6.78 \mathrm{mmol})$ of tetracosanoic acid was mixed with $0.3 \mathrm{~g}(9.68 \mathrm{mmol})$ of red phosphorus and the mixture was heated to $95^{\circ} \mathrm{C} .1 .5 \mathrm{ml}(29 \mathrm{mmol})$ of $\mathrm{Br}_{2}$ was added and the reaction mixture was stirred at $95^{\circ} \mathrm{C}$ overnight. The reaction was quenched by addition of water, and the solution was stirred at RT for additional 30 minutes. The crude product was extracted with diethyl ether $(3 \times 100 \mathrm{ml})$, then the organic phase was extracted with saturated solution of $\mathrm{Na}_{2} \mathrm{~S}_{2} \mathrm{O}_{3}(1 \times 100 \mathrm{ml})$, dried over $\mathrm{Na}_{2} \mathrm{SO}_{4}$, and the solvent was evaporated. The product was purified using column chromatography with a mobile phase consisting of hexane/ethyl acetate $10: 1$ with addition of $0.5 \%$ acetic acid to yield $2.94 \mathrm{~g}$ (97\%) of 2-bromotetracosanoic acid as a white solid.

${ }^{1} \mathrm{H}$ NMR $\left(600 \mathrm{MHz}, \mathrm{CDCl}_{3}\right) \delta 4.23(\mathrm{t}, \mathrm{J}=7.3 \mathrm{~Hz}, 1 \mathrm{H}), 2.13-2.03(\mathrm{~m}, 1 \mathrm{H}), 2.03-1.93(\mathrm{~m}$, $1 \mathrm{H}), 1.56-1.43(\mathrm{~m}, 2 \mathrm{H}), 1.43-1.18(\mathrm{~m}, 38 \mathrm{H}), 0.87(\mathrm{t}, \mathrm{J}=7.0 \mathrm{~Hz}, 3 \mathrm{H}) .{ }^{13} \mathrm{C} \mathrm{NMR}(151 \mathrm{MHz}$, $\left.\mathrm{CDCl}_{3}\right) \delta$ 175.34, 45.38, 34.75, 32.01, 29.78, 29.75, 29.72, 29.67, 29.55, 29.45, 29.37, $28.89,27.27,22.77,14.20$. Other characteristics were in accordance to the literature. ${ }^{1}$

$2.94 \mathrm{~g}(6.56 \mathrm{mmol})$ of 2-bromotetracosanoic acid was suspended in $50 \mathrm{ml}$ of $2 \mathrm{M} \mathrm{NaOH}$, and the reaction mixture was stirred at $85{ }^{\circ} \mathrm{C}$ for 48 hours. The reaction mixture was acidified with $\mathrm{HCl}$ to $\mathrm{pH} 1$, and extracted with diethyl ether $(4 \times 100 \mathrm{ml})$. The organic phase was dried 
over $\mathrm{Na}_{2} \mathrm{SO}_{4}$ and evaporated. The product was purified using column chromatography with a mobile phase consisting of $\mathrm{CHCl}_{3} / \mathrm{MeOH} 20: 1$ to yield $2.05 \mathrm{~g}(81 \%)$ of 2hydroxytetracosanoic acid as a white solid. ${ }^{1} \mathrm{H}$ NMR $(500 \mathrm{MHz}, \mathrm{CDCl} / \mathrm{MeOD} 5: 1) \delta 4.11-$ $4.03(\mathrm{~m}, 1 \mathrm{H}), 1.78-1.65(\mathrm{~m}, 2 \mathrm{H}), 1.40-1.29(\mathrm{~m}, 2 \mathrm{H}), 1.28-1.11(\mathrm{~m}, 38 \mathrm{H}), 0.80(\mathrm{t}, \mathrm{J}=7.0$ $\mathrm{Hz}, 3 \mathrm{H}) .{ }^{13} \mathrm{C} \mathrm{NMR}\left(126 \mathrm{MHz}, \mathrm{CDCl}_{3} / \mathrm{MeOD} 5: 1\right) \delta$ 177.03, 70.10, 38.96, 34.06, 31.69, 29.46, $29.42,29.38,29.33,29.28,29.25,29.16,29.12,28.83,27.34,24.70,22.44,13.78$. Other characteristics were in accordance to the literature. ${ }^{1}$

$800 \mathrm{mg}(2.08 \mathrm{mmol})$ of 2-hydroxytetracosanoic acid was mixed with $720 \mathrm{mg}(2.27 \mathrm{mmol})$ of phytosphingosine and $840 \mathrm{mg}(6.22 \mathrm{mmol})$ of 1-hydroxybenzotriazol hydrate, dried over vacuum, dissolved in $160 \mathrm{ml}$ of dry THF and $320 \mathrm{ml}$ of dry $\mathrm{CH}_{2} \mathrm{Cl}_{2}$, and cooled down to $0{ }^{\circ} \mathrm{C}$ under an $\mathrm{Ar}$ atmosphere. $736 \mu \mathrm{l}(4.16 \mathrm{mmol})$ of $\mathrm{N}$-(3-Dimethylaminopropyl)- $N$ 'ethylcarbodiamide was added, the reaction mixture was slowly warmed to RT and stirred overnight at RT under Ar atmosphere. Solvents were evaporated and the crude product was purified using column chromatography with a mobile phase consisting of $\mathrm{CHCl}_{3} / \mathrm{MeOH} 50: 1$ to yield $587 \mathrm{mg}(83 \%)$ of the (D)-isomer and $592 \mathrm{mg}(83 \%)$ of the (L)-isomer of ceramide AP as white solids.

Characterization of the (R)-isomer: ${ }^{1} \mathrm{H}$ NMR $\left(500 \mathrm{MHz}, \mathrm{CDCl}_{3}\right) \delta 7.14(\mathrm{~d}, \mathrm{~J}=7.7 \mathrm{~Hz}, 1 \mathrm{H})$, $4.21-4.10(\mathrm{~m}, 2 \mathrm{H}), 3.98(\mathrm{dd}, \mathrm{J}=11.6,3.1 \mathrm{~Hz}, 1 \mathrm{H}), 3.82(\mathrm{dd}, \mathrm{J}=11.5,5.1 \mathrm{~Hz}, 1 \mathrm{H}), 3.75-$ $3.59(\mathrm{~m}, 2 \mathrm{H}), 1.95-1.80(\mathrm{~m}, 2 \mathrm{H}), 1.78-1.61(\mathrm{~m}, 2 \mathrm{H}), 1.56-1.40(\mathrm{~m}, 18 \mathrm{H}), 1.41-1.24$ $(\mathrm{m}, 46 \mathrm{H}), 0.90(\mathrm{t}, \mathrm{J}=6.9 \mathrm{~Hz}, 6 \mathrm{H}) .{ }^{13} \mathrm{C} \mathrm{NMR}\left(126 \mathrm{MHz}, \mathrm{CDCl}_{3}\right) \delta 174.77,76.60,73.00,72.38$, $62.27,53.16,35.14,33.37,31.95,29.71,29.67,29.54,29.42,29.35,25.68,25.02,22.67$, 14.01. IR 3331, 3199, 2917, 2849, 1619, 1545, 1466, 1356, 1277, 1070, 1022, $723 \mathrm{~cm}^{-1}$. Melting point: $136-138{ }^{\circ} \mathrm{C}$. Elemental analysis $\left(\mathrm{M}+2 \mathrm{H}_{2} \mathrm{O}\right)$, calculated: $\mathrm{C} 70.05, \mathrm{H} 12.46, \mathrm{~N}$ 1.94, O 15.55; measured: C 70.08, H 12.09, N 2.03, O 15.80.

\subsection{Purification and separation of symmetric technical CER[AP]}

The racemic CER[AP] was absorbed on a small amount of silica gel (SiO2:CER 2:1) and separated by column chromatography with fresh distilled chloroform and methanol (SiO2:CERrac 200:1; CHCl3:MeOH:0.5\%V/V NH3aq 96.5:3.5 for (L-CER[AP]) followed by 94:6 for (D-CER[AP])). The separation process was followed by thin layer chromatography (CHCl3:MeOH:NH3aq 90:10:0.5 Rf=0.50 (L-CER[AP]), 0.24 (D-CER[AP])). The purity of the L- and D-form was also checked by HPLC. 


\section{D-CER[AP] supramolecular lattice description}

D-CER[AP] with symmetric and asymmetric chains form an oblique chain lattice in monolayers. The presence of extra peaks indicates the formation of a supramolecular lattice (subgel phase) due to intermolecular hydrogen bonding network. Lorentzian function have been fitted to the experimentally observed scattering peaks (figure S1). The peak positions are the same for both symmetric and asymmetric D-CER[AP]. In figure $\mathrm{S} 1$ the Miller indices of each Bragg peak are indicated. The calculated values are presented in table S2.

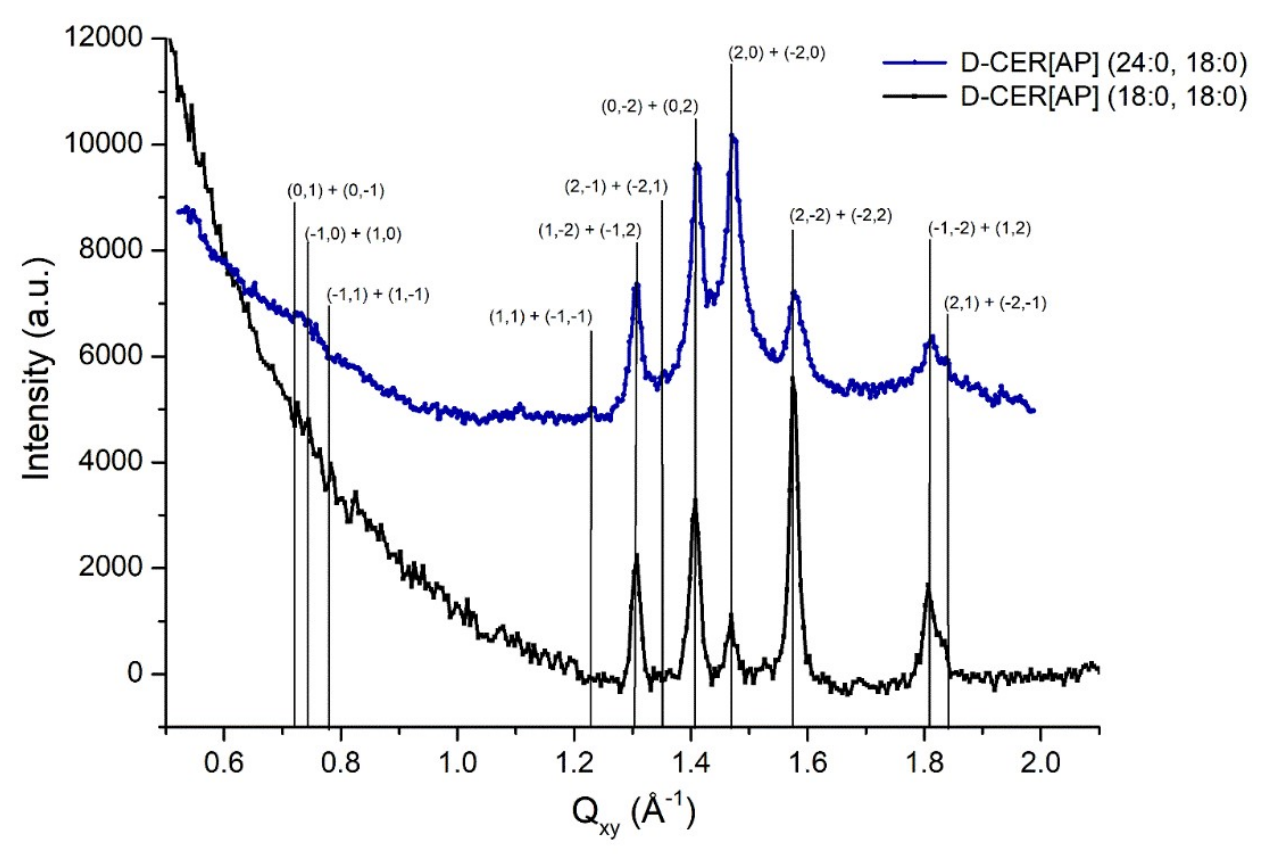

Figure S1. Positions with Miller indices of the calculated Bragg peaks (table S2) together with the experimentally observed scattering profiles of monolayers of D-CER[AP] with symmetric chains (black curve) and asymmetric chains (blue curve). The experiments have been performed at $20{ }^{\circ} \mathrm{C}$ and $20 \mathrm{mN} / \mathrm{m}$. 


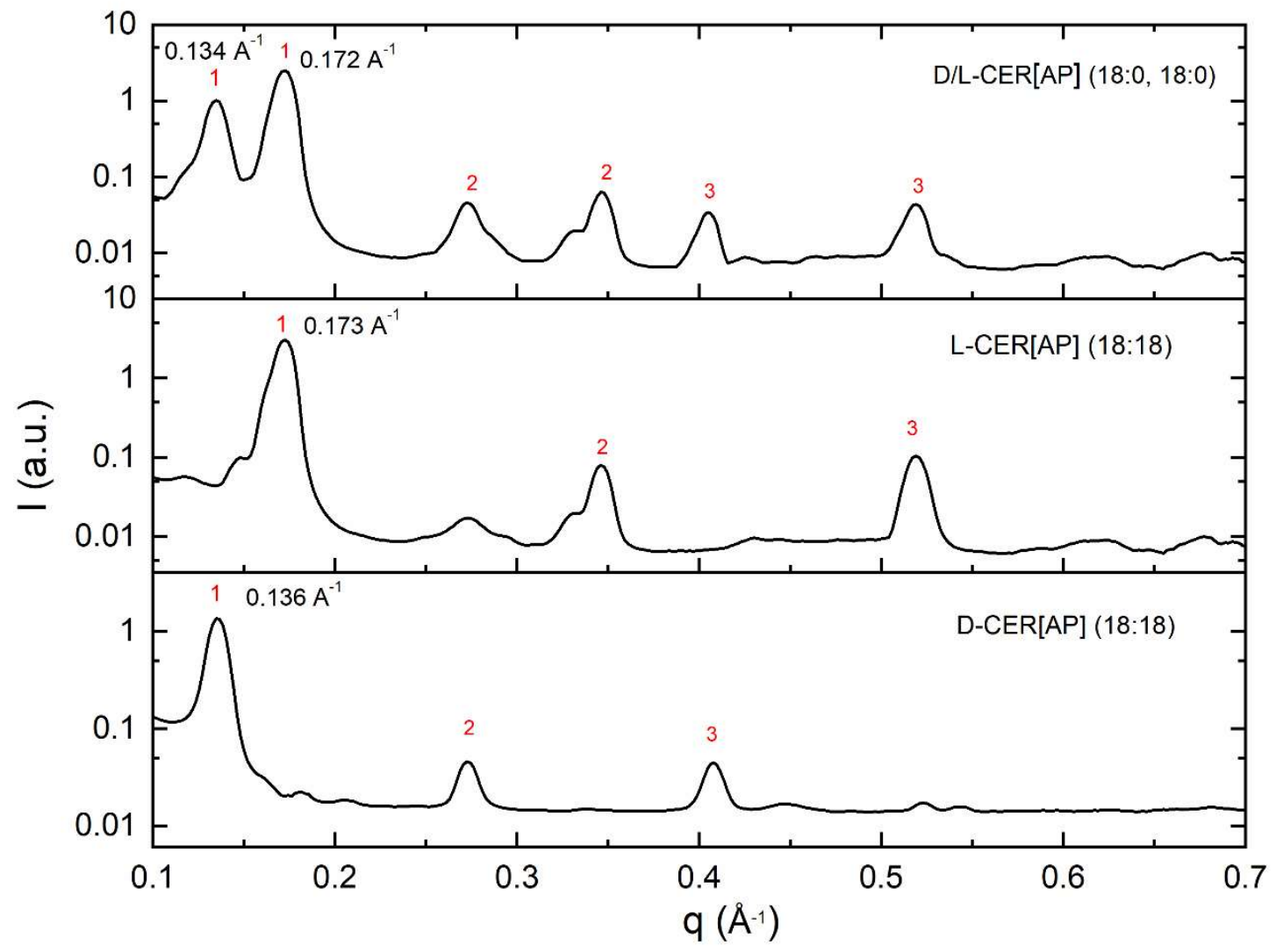

Figure S2. Small-angle X-ray scattering profiles of D/L-CER[AP], L- CER[AP] and D- CER[AP] with symmetric chains (C18:C18) recorded at $20^{\circ} \mathrm{C}$.

\section{FTIR analysis of dry samples}

FTIR spectroscopy was selected as tool to get additional information about structural properties which might help to understand better the calorimetric results. The properties of dry powders before and after melting have been investigated at room temperature. In figures $\mathrm{S} 3 \mathrm{a}$ and $\mathrm{S} 3 \mathrm{~b}$, the $\mathrm{CH}_{2}$ stretching modes of symmetric and asymmetric CER[AP] before melting are presented. The observed wavenumbers below $2850 \mathrm{~cm}^{-1}$ (table S3) and 2920 $\mathrm{cm}^{-1}$ were indicative of highly ordered all-trans chains denoting a crystalline packing. ${ }^{2}$ Nevertheless, D-CER[AP] exhibits slightly lower wavenumbers in comparison to the LCER[AP]. As showed in the main text, the amide I and II modes indicated that D-CER[AP] was able to create hydrogen bonds while L-CER[AP] did not, similarly to what observed in WAXS experiments with hydrated samples. 

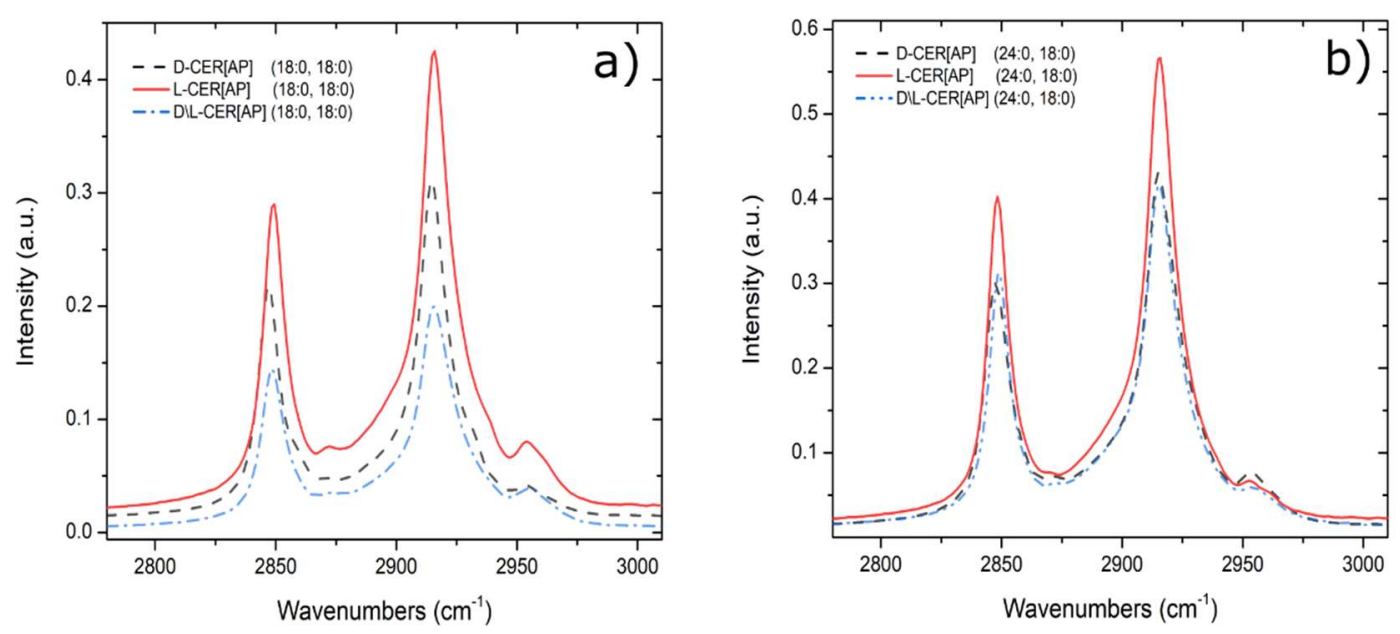

Figure S3. FTIR profiles of $\mathrm{v}_{\text {sym }} \mathrm{CH}_{2}$ stretching and $\mathrm{v}_{\text {asym }} \mathrm{CH}_{2}$ stretching $(\mathrm{a}, \mathrm{b})$ registered at room temperature. Lorentz function has been used to determine the centre of each band.

The $\delta \mathrm{CH}_{2}$ scissoring mode identifies the packing properties in the phases on hand. ${ }^{3} \mathrm{~A}$ single peak at $\sim 1465 \mathrm{~cm}^{-1}$ for symmetric and asymmetric D-CER[AP] was representative for a hexagonal packing, while the L-CER[AP] presented a splitting of the peak with centers at 1456 and $1470 \mathrm{~cm}^{-1}$ what was a clear sign of an orthorhombic packing. The splitting was less noticeable in the diastereomers mixture due to the co-existence of the two packing modes. The findings obtained with FTIR spectroscopy were in good agreement with SAXS/WAXS data measured in hydrated samples. The D-CER[AP] head groups form a $\mathrm{HbN}$ and stabilize a hexagonal packing of lipids which order in a hairpin configuration. L-CER[AP] molecules do not form the $\mathrm{HbN}$ thus stabilizing in an orthorhombic packing with chains organized in a V-shape or tilted hairpin. 

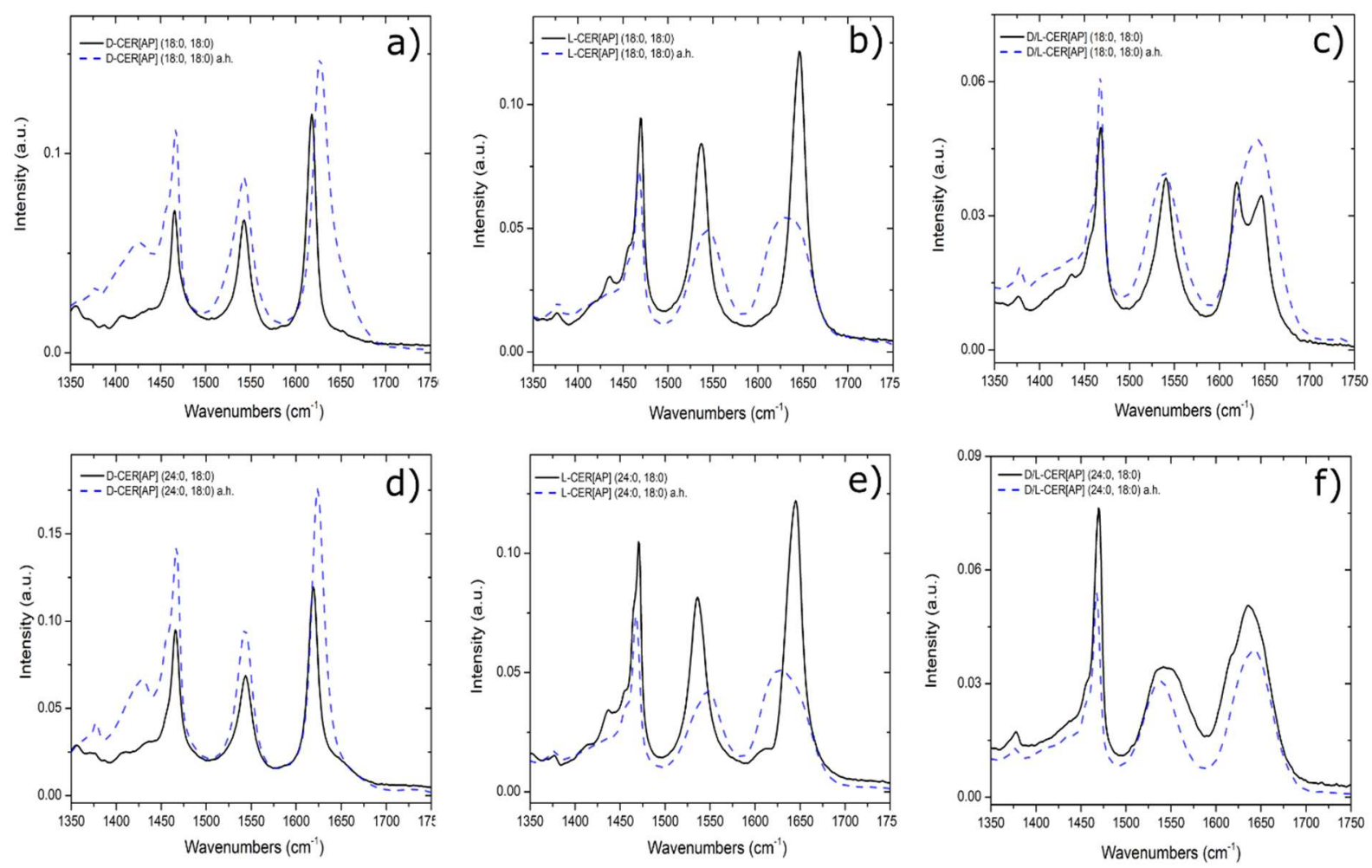

Figure S4. FTIR amide region of symmetric and asymmetric CER[AP] diastereomers at room temperature before and after recrystallization from the melt ( 3 heating and cooling scans from $20^{\circ} \mathrm{C}$ to $200{ }^{\circ} \mathrm{C}$ were applied).

To study the structural properties of metastable phases of CER[AP], FTIR was additionally recorded at room temperature after heating the samples to $200{ }^{\circ} \mathrm{C}$ to analyze the phases formed after crystallization from the melt. The D-CER[AP] (figures S4a and S4d) showed mainly changes in the amide I wavenumbers which increased by $6 \mathrm{~cm}^{-1}$ and $10 \mathrm{~cm}^{-1}$, respectively, for the asymmetric and symmetric forms, however, only small variations ( $\sim 1$ $\mathrm{cm}^{-1}$ ) for the amide II mode suggested a partial disruption of the $\mathrm{HbN}$. A direct consequence of the $\mathrm{HbN}$ disruption was the splitting of the $\delta \mathrm{CH}_{2}$ peak indicating a change from hexagonal to orthorhombic packing after D-CER[AP] recrystallization. The recrystallized L-CER[AP] (figures 10b and 10e) presented shifted and broader amide I and II bands suggesting the formation of a crystal with weak $\mathrm{HbN}$. Finally, FTIR analysis of the two 1:1 mixtures (figures S4c and S4d) documented the miscibility of the diastereomers by the merging of the bands both in the amide I and II regions. 
Table S1. Structural parameters extracted from GIXD data. Lattice parameters $(a, b, c)$ and $(\alpha, \beta, \gamma)$, lattice distortion $(\mathrm{d})$, chain tilt $(\mathrm{t})$, in-plane $\left(A_{x y}\right)$ and cross sectional area $\left(\mathrm{A}_{0}\right)$ measured at $20^{\circ} \mathrm{C}$ on water. The lateral pressure $\pi$ is indicated.

\begin{tabular}{|c|c|c|c|c|c|c|c|}
\hline & $\begin{array}{c}\pi \\
(\mathrm{mN} / \mathrm{m})\end{array}$ & $\begin{array}{c}a, b, c \\
\AA\end{array}$ & $\alpha, \beta, \gamma$ & $d$ & $\begin{array}{l}\mathrm{t} \\
\mathrm{\circ}\end{array}$ & $\begin{array}{l}A_{x y} \\
\AA^{2}\end{array}$ & $\begin{array}{l}A_{0} \\
\AA^{2}\end{array}$ \\
\hline $\begin{array}{c}\text { L-CER[AP] } \\
(18: 18)\end{array}$ & 20 & $\begin{array}{l}4.482 \\
4.850 \\
5.502\end{array}$ & $\begin{array}{l}129.2 \\
123.0 \\
107.9\end{array}$ & 0.24307 & 20.3 & 20.7 & 19.4 \\
\hline $\begin{array}{c}\text { L-CER[AP] } \\
(24: 18)\end{array}$ & 20 & $\begin{array}{l}4.637 \\
4.961 \\
5.534\end{array}$ & $\begin{array}{l}127.9 \\
122.4 \\
109.7\end{array}$ & 0.20921 & 24.8 & 21.7 & 19.7 \\
\hline $\begin{array}{c}\text { D-CER[AP] } \\
(18: 18)\end{array}$ & 20 & $\begin{array}{l}4.667 \\
4.873 \\
5.221\end{array}$ & $\begin{array}{l}125.0 \\
121.3 \\
113.7\end{array}$ & 0.13199 & 14.1 & 20.8 & 20.2 \\
\hline $\begin{array}{c}\text { D-CER[AP] } \\
(24: 18)\end{array}$ & 30 & $\begin{array}{l}4.667 \\
4.873 \\
5.221\end{array}$ & $\begin{array}{l}125.0 \\
121.3 \\
113.7\end{array}$ & 0.13199 & 14.7 & 20.8 & 20.1 \\
\hline $\begin{array}{c}\text { D/L-CER[AP] } \\
(18: 18) \\
\text { Phase } 1\end{array}$ & 20 & $\begin{array}{l}4.688 \\
4.853 \\
5.180\end{array}$ & $\begin{array}{l}124.4 \\
121.3 \\
114.3\end{array}$ & 0.11855 & 14.6 & 20.7 & 20.1 \\
\hline $\begin{array}{c}\text { D/L-CER[AP] } \\
(18: 18) \\
\text { Phase } 2\end{array}$ & 20 & $\begin{array}{l}4.444 \\
4.839 \\
5.603\end{array}$ & $\begin{array}{l}130.3 \\
123.8 \\
105.9\end{array}$ & 0.27655 & 16.5 & 20.7 & 19.8 \\
\hline $\begin{array}{c}\text { D/L-CER[AP] } \\
(24: 18) \\
\text { Phase } 1\end{array}$ & 20 & $\begin{array}{l}4.739 \\
4.838 \\
5.170\end{array}$ & $\begin{array}{l}123.6 \\
121.7 \\
114.7\end{array}$ & 0.10701 & 15.1 & 20.8 & 20.1 \\
\hline $\begin{array}{c}\text { D/L-CER[AP] } \\
(24: 18) \\
\text { Phase } 2\end{array}$ & 20 & $\begin{array}{l}4.600 \\
4.934 \\
5.524\end{array}$ & $\begin{array}{l}128.2 \\
122.5 \\
109.3\end{array}$ & 0.21674 & 18.4 & 21.4 & 20.3 \\
\hline
\end{tabular}


Table S2. In-plane peak positions and calculated (quadratic Bragg equation of a triclinic system) Miller indices for symmetric and asymmetric D-CER[AP] in monolayers. A supramolecular lattice with $a_{\mathrm{s}}=9.356 \AA, b_{\mathrm{s}}=9.754 \AA, \gamma=114.0^{\circ}$ has been used. The unit cell with an area of $83.4 \AA$ accommodates $2 \mathrm{D}-\mathrm{CER}[\mathrm{AP}]$ molecules.

\begin{tabular}{|c|c|}
\hline $\begin{array}{c}\text { Qxy, } \\
\AA^{-1}\end{array}$ & Miller Indices \\
\hline 0.71 & $(0,1)+(0,-1)$ \\
\hline 0.74 & $(-1,0)+(1,0)$ \\
\hline 0.78 & $(-1,1)+(1,-1)$ \\
\hline 1.21 & $(1,1)+(-1,-1)$ \\
\hline 1.30 & $(1,-2)+(-1,2)$ \\
\hline 1.35 & $(2,-1)+(-2,1)$ \\
\hline 1.41 & $(0,-2)+(0,2)$ \\
\hline 1.47 & $(2,0)+(-2,0)$ \\
\hline 1.57 & $(2,-2)+(-2,2)$ \\
\hline 1.84 & $(-1,-2)+(1,2)$ \\
\hline 1.87 & $(2,1)+(-2,-1)$ \\
\hline
\end{tabular}

Table S3. Bragg peak positions and fwhm (Lorentzian function) from WAXS profiles of asymmetric D- and L-CER[AP]. Calculated peak positions with corresponding Miller indices.

\begin{tabular}{|c|c|c|c|c|}
\hline $\begin{array}{c}\text { D-CER[AP] (24:0, 18:0) } \\
\AA^{-1}\end{array}$ & $\begin{array}{c}\text { fwhm } \\
\AA^{-1}\end{array}$ & $\begin{array}{c}\text { Calculated } \\
\text { positions with Miller } \\
\text { indices }\end{array}$ & $\begin{array}{c}\text { L-CER[AP] }(24: 0,18: 0) \\
\AA^{-1}\end{array}$ & $\begin{array}{c}\text { fwhm } \\
\AA^{-1}\end{array}$ \\
\hline 0.74 & 0.044 & $0.70(0,-1)+(0,1)$ & 1.37 & 0.080 \\
\hline 0.94 & 0.047 & $0.94(-2,1)+(2,-1)$ & 1.52 & 0.10 \\
\hline 1.00 & 0.045 & $1.00(-2,0)+(2,0)$ & 1.62 & 0.15 \\
\hline 1.05 & 0.050 & $1.02(-1,-1)+(1,1)$ & - & - \\
\hline 1.17 & 0.050 & $1.26(1,-2)+(-1,2)$ & - & - \\
\hline 1.30 & 0.038 & $1.32(2,-2)+(-2,2)$ & - & - \\
\hline 1.37 & 0.045 & $1.35(3,-1)+(-3,1)$ & - & - \\
\hline 1.40 & 0.032 & $1.40(0,2)+(0,-2)$ & - & - \\
\hline
\end{tabular}




\begin{tabular}{|c|l|l|l|l|}
\hline 1.50 & 0.050 & $1.50(3,0)+(-3,0)$ & - & - \\
\hline 1.54 & 0.050 & $1.54(-3,2)+(3,-2)$ & - & - \\
\hline
\end{tabular}

The experimentally observed Bragg peaks of D-CER[AP] $(24: 0,18: 0)$ in aqueous dispersions can be satisfactorily described with a supramolecular lattice accommodating 3 molecules: $a_{s}=13.977 \AA$, $b_{s}=9.984 \AA$ and $y=115.9^{\circ}$.

Table S4. Wavenumbers of the $\mathrm{CH}_{2}$ stretching and scissoring bands as well as of the amide region bands. The abbreviation a.h. indicates samples measured at room temperature after one heating cycle to $200^{\circ} \mathrm{C}$.

\begin{tabular}{|c|c|c|c|c|}
\hline & $\begin{array}{c}-\mathrm{CH}_{2} \text { symm. } \\
\text { Stretching } \\
\left(\mathrm{cm}^{-1}\right)\end{array}$ & $\begin{array}{c}-\mathrm{CH}_{2} \\
\text { Scissoring } \\
\left(\mathrm{cm}^{-1}\right)\end{array}$ & $\begin{array}{l}\text { Amide I } \\
\left(\mathrm{cm}^{-1}\right)\end{array}$ & $\begin{array}{c}\text { Amide II } \\
\left(\mathrm{cm}^{-1}\right)\end{array}$ \\
\hline $\begin{array}{c}\text { D-CER[AP] } \\
(18: 0,18: 0)\end{array}$ & 2847.4 & 1465.4 & 1617.7 & 1542.3 \\
\hline $\begin{array}{c}\text { D-CER[AP] } \\
(18: 0,18: 0) \text { a.h. }\end{array}$ & 2850.7 & $\begin{array}{l}1456.4 \\
1466.9\end{array}$ & 1627.3 & 1541.3 \\
\hline $\begin{array}{l}\text { L-CER[AP] } \\
(18: 0,18: 0)\end{array}$ & 2849.3 & $\begin{array}{l}1456.5 \\
1470.2\end{array}$ & 1645.3 & 1536.3 \\
\hline $\begin{array}{c}\text { L-CER[AP] } \\
(18: 0,18: 0) \text { a.h- }\end{array}$ & 2849.5 & $\begin{array}{l}1457.2 \\
1467.2\end{array}$ & 1630.5 & 1542.9 \\
\hline $\begin{array}{c}\text { DIL-CER[AP] } \\
(18: 0,18: 0)\end{array}$ & 2948.9 & $\begin{array}{l}1457.5 \\
1467.8\end{array}$ & $\begin{array}{c}1619.6 \\
1645.1\end{array}$ & 1540.4 \\
\hline $\begin{array}{r}\text { DIL-CER[AP] } \\
(18: 0,18: 0) \text { a.h. }\end{array}$ & 2849.5 & $\begin{array}{l}1456.4 \\
1467.8\end{array}$ & 1640.5 & 1538.6 \\
\hline $\begin{array}{l}\text { D-CER[AP] } \\
(24: 0,18: 0)\end{array}$ & 2848.1 & 1464.8 & 1618.4 & 1543.1 \\
\hline $\begin{array}{c}\text { D-CER[AP] } \\
(24: 0,18: 0) \text { a.h. }\end{array}$ & 2850.6 & $\begin{array}{l}1456.3 \\
1467.1\end{array}$ & 1624.4 & 1542.9 \\
\hline $\begin{array}{l}\text { L-CER[AP] } \\
(24: 0,18: 0)\end{array}$ & 2848.6 & $\begin{array}{l}1456.3 \\
1470.0\end{array}$ & 1643.6 & 1536.6 \\
\hline $\begin{array}{c}\text { L-CER[AP] } \\
(24: 0,18: 0) \text { a.h. }\end{array}$ & 2849.7 & $\begin{array}{l}1456.9 \\
1466.8\end{array}$ & 1630.8 & 1545.3 \\
\hline $\begin{array}{c}\text { DIL-CER[AP] } \\
(24: 0,18: 0)\end{array}$ & 2849.2 & $\begin{array}{l}1456.0 \\
1469.6\end{array}$ & $\begin{array}{l}1615.3 \\
1640.2\end{array}$ & $\begin{array}{c}1538.5 \\
1561.2\end{array}$ \\
\hline $\begin{array}{c}\text { DIL-CER[AP] } \\
(24: 0,18: 0) \text { a.h. }\end{array}$ & 2849.8 & $\begin{array}{l}1456.1 \\
1467.5\end{array}$ & 1640.7 & 1538.2 \\
\hline
\end{tabular}


References.

(1) Masuda, Y.; Mori, K. Synthesis and Absolute Configuration of 6-Hydroxylated New Ceramides in Human Skin , Ceramides B , 4 , 7 and 8 [†]. 2005, 4789-4800. https://doi.org/10.1002/ejoc.200500357.

(2) MacPhail, R. A.; Strauss, H. L.; Snyder, R. G.; Eiliger, C. A. C-H Stretching Modes and the Structure of n-Alkyl Chains. 2. Long, All-Trans Chains. J. Phys. Chem. 1984, 88 (3), 334-341. https://doi.org/10.1021/j150647a002.

(3) Rerek, M. E.; Chen, H.; Markovic, B.; Wyck, D. Van; Garidel, P.; Mendelsohn, R.; Moore, D. J. Phytosphingosine and Sphingosine Ceramide Headgroup Hydrogen Bonding : Structural Insights through Thermotropic Hydrogen / Deuterium Exchange. J. Phys. Chem. B 2001, 105 (38), 9355-9362. https://doi.org/10.1021/jp0118367. 